\title{
OS PRINCÍPIOS COOPERATIVISTAS E A INTERDISCIPLINARIDADE PRESENTES EM UMA COOPERATIVA ESCOLAR
}

\author{
THE COOPERATIVE PRINCIPLES AND INTERDISCIPLINARITY PRESENT IN A \\ SCHOOL COOPERATIVE
}

\begin{abstract}
Danieli de Oliveira Biolchi
Universidade Regional do Noroeste do Estado do Rio Grande do Sul, RS, Brasil, danieli.biolchi@ unijui.edu.br
\end{abstract}

Airton Adelar Mueller

Universidade Regional do Noroeste do Estado do Rio Grande do Sul, RS, Brasil, airton.mueller@ unijui.edu.br

\section{Nelson José Thesing}

Universidade Regional do Noroeste do Estado do Rio Grande do Sul, RS, Brasil, nelson.thesing@ unijui.edu.br

\section{Danieli de Almeida Oliveira}

Universidade Regional do Noroeste do Estado do Rio Grande do Sul, RS, Brasil, danieli.oliveira@sou. unijui.edu.br

DOI: http://dx.doi.org/10.31512/gesto.v10i1.554 Recebido em: 07/10//2021 $\quad$ Aceito em: 12/11/2021

Resumo: $\mathrm{O}$ presente artigo busca compreender as contribuiçóes dos princípios do cooperativismo, a interdisciplinaridade, em um processo de construção coletivo, efetivado na prática, na realização do Projeto Educacional. Significa verificar, para além das fundamentaçóes teóricas, construídas ao longo da história, identificar as práticas da constituição de uma Cooperativa Escolar, por alunos na Escola Municipal de Ensino Fundamental Imaculada Conceição, no distrito do Depósito, no município de Espumoso, fundada em 2018. Para responder os objetivos do estudo, a pesquisa conta com aportes teóricos-metodológicos, de natureza aplicada, abordagem qualitativa, com a análise de conteúdo. Os achados do estudo indicam que os princípios, as concepçóes de estudos interdisciplinares, se efetivam, ao contribuírem na constituição de uma cooperativa escolar, com açôes de intervenção da realidade, ao produzir o sal temperado, para uma comunidade com altos índices de hipertensão, ao promover o protagonismo de estudantes, ao exercerem a autogestão na cooperativa, ao incorporar na caminhada educacional, professores, funcionários, pais e a comunidade, em um conjunto de atividades, com apoio da Secretaria Municipal de Educação, tendo como eixos norteadores, a solidariedade, a cooperação e interesse pela comunidade, contribuindo com a efetivação dos princípios cooperativistas, nas boas práticas de governança cooperativa, na interdisciplinaridade, fundamentais na construção do conhecimento.

Palavras-chave: Educação. Princípios Cooperativistas. Interdisciplinaridade

Abstract: This article seeks to understand the contributions of the principles of cooperativism, interdisciplinarity, in a process of collective construction, carried out in practice, in carrying out the Educational Project. It means, looking beyond the theoretical foundations, built throughout history, to identify the practices of the constitution of a School Cooperative, by students at the Municipal Elementary 
School Imaculada Conceição, in the district of Depósito, in the municipality of Espumoso, founded in 2018. To meet the study objectives, the research has theoretical-methodological contributions, of an applied nature, qualitative approach, with content analysis. The findings of the study indicate that the principles, the conceptions of interdisciplinary studies, are effective, by contributing to the constitution of a school cooperative, with actions to intervene in reality, by producing seasoned salt, for a community with high rates of hypertension, by to promote the protagonism of students, by exercising self-management in the cooperative, by incorporating teachers, employees, parents and the community into the educational journey, in a set of activities, with the support of the Municipal Department of Education, with solidarity as its guiding principles, cooperation and interest in the community, contributing to the realization of cooperative principles, in good practices of cooperative governance, in interdisciplinarity, fundamental in the construction of knowledge.

Keywords: Education. Cooperative Principles. Interdisciplinarity.

\section{Introdução} Darte-se do pressuposto de que, em um processo de pesquisa, em busca de uma
compreensão, no campo do cooperativismo, especialmente ao verificar a formaçáo de uma Cooperativa Escolar, por alunos na Escola Municipal de Ensino Fundamental Imaculada Conceição, no distrito do Depósito, no município de Espumoso, fundada em 2018, é indispensável empreender ações coletivas, presente na humanidade ao longo da história, que auxiliaram e promoveram a sobrevivência das espécies (GAMBETTA, 1996). Portanto, tem-se presente que cooperação está ligada ao processo evolutivo da humanidade, bem como a mudança profundas que se efetivam ao longo da história, que se desenvolveram em um movimento que trilha pelas açóes coletivas, um caminhar que pode ser extremamente importante no processo na compreensão dos princípios cooperativistas e da interdisciplinaridade escolar, fortalecendo açóes pedagógicas.

Para Fazenda (1999), o termo interdisciplinaridade nasce na Europa, em meados da década de 1960, época em que as organizaçóes estudantis ganhavam força na busca de um novo estatuto das universidades. Este movimento visava a integraçáo das disciplinas, o inter-relacionamento e a cooperação entre as diversas áreas do conhecimento. Um processo que apontava um novo olhar para a educação, uma nova forma de lecionar as disciplinas, buscando um ensino que integrasse as diversas áreas do conhecimento. Desde então, as açôes interdisciplinares buscam a construção de uma educação que possa ter mais qualidade, que promova a equidade e igualdade entre as classes. Um caminhar que pode contribuir em açôes coletivas, de cooperação criando cada vez mais um ambiente para o desenvolvimento de atuaçôes interdisciplinares. Desta forma, busca-se a integração da interdisciplinaridade e os sete princípios do cooperativismo: Adesão Livre e Voluntária; Gestão Democrática; Participação Econômica; Autonomia e Independência; Educação, Formação e Informação; Intercooperação; Interesse pela Comunidade.

Sendo assim, o estudo apresenta como objetivo central, compreender as possíveis relaçóes que se podem estabelecer entre os sete princípios cooperativistas e a interdisciplinares, presentes na formação de uma Cooperativa Escolar, por alunos na Escola Municipal de Ensino Fundamental Imaculada Conceição, no distrito do Depósito. 
Para uma melhor compreensão do objetivo deste artigo, o mesmo está estruturado, além desta Introdução; do Referencial Teórico; Caminhos Metodológicos; Análise e Discussão dos Resultados; seguido das Consideraçôes Finais; e por fim, traz as Referências.

\section{Fundamentaçóes teórias}

\subsection{Governança cooperativa}

Ao buscar a compreensão de como foi constituída a Cooperativa Escolar, tem-se presente a importância da cooperação, seja ela dos caminhos da governança cooperativa ou em projetos interdisciplinares, há que se olhar também para a história. Em pesquisas que trilham olhares para a literatura internacional encontram-se diferentes abordagens sobre governança. Sáo apresentadas concepçóes que defendem o caráter empresarialista, a governança urbana, a governança democrática e compartilhada entre os atores sociais, institucionais, governamentais e empresariais (DALLABRIDA, 2015). Para Rossetti e Andrade (2012), a governança possui abordagens que podem ser expressas pelas oito dimensóes, ou seja, os P's da governança: "Propriedade, Princípios, Propósitos, Papéis, Poder, Práticas, Perenidade e Pessoas" (ROSSETTI; ANDRADE, 2012 p. 144).

No entanto, este estudo está voltado para a governança cooperativa. Cooperativa é uma sociedade de pessoas, em que cada associado tem direito a um voto, diferentemente das sociedades de capital, em que o voto é proporcional ao capital de cada investidor. Ocorre que, dessa diferenciaçáo decorrem diversas implicaçôes no processo de gestáo em cooperativas (FRANCISCO FILHO; LINS, 2012). Já para Schneider (2012), as cooperativas apontam um diferencial em sua formação, como uma entidade social coletiva, que necessita trabalhar em cooperação, com princípios de solidariedade, para suprir a crescente satisfaçáo das necessidades e bem-estar dos associados.

Assim, tem-se presente também o Manual de Boas Práticas de Governança para Cooperativas, estabelecido pela Organização das Cooperativas Brasileiras (OCB):

É um modelo de direção estratégica, fundamentado nos valores e princípios cooperativistas, que estabelece práticas éticas visando garantir a consecução dos objetivos sociais e assegurar a gestáo da cooperativa de modo sustentável em consonância com os interesses dos cooperados.

[...] a adoção da boa prática de Governança na Cooperativa garante a aplicação da autogestâo no Sistema Cooperativista Nacional e tem por finalidades: a) ampliar a transparência da administração da sociedade cooperativa; b) facilitar o desenvolvimento e a competitividade das cooperativas; c) contribuir para a sustentabilidade e perenidade do modelo cooperativista; d) aprimorar a participação do cooperado no processo decisório; e) obter melhores resultados econômico-financeiros; f) incentivar a inovaçáo e proporcionar a melhoria da qualidade dos serviços ao quadro social; g) aplicar a responsabilidade social como integraçăo da cooperativa com a Sociedade civil (OCB, 2016, p. 12).

Tem-se presente as diversas literaturas que tratam de estudos sobre governança cooperativa. Para Pinto e Reisdorfer (2015), a governança cooperativa indica caminhos pelos quais devem ser orientadas as práticas cooperativadas. Neste sentido, indicam, que as práticas 
podem ser entendidas como um conjunto de processos, políticas, leis e regulamentos que orientam a governança. No entanto, esse processo necessita ser alimentado pelos sete princípios do cooperativismo, são destacados no Manual de Boas Práticas de Governança para Cooperativas (OCB, 2016).

Desta maneira, merece registro que desde a fundação do cooperativismo moderno, em 1844 na Inglaterra, todavia, os princípios orientam as ações das cooperativas em nível mundial, bem como, são reavaliados constantemente, sendo a última avaliação foi realizada pela Aliança Cooperativa Internacional (ACI), em 1995, como linhas orientadoras de ação, para fortalecer as práticas e os valores de democracia, liberdade, equidade, solidariedade e justiça social. Assim, os princípios permanecem vigentes nas cooperativas e no O Manual das Melhores Práticas de Governança para Cooperativas (2016, p.16-17-18), descreve os princípios cooperativistas, conforme segue:

I. Adesão Voluntária e Livre: As cooperativas são organizaçóes voluntárias, abertas a todas as pessoas aptas a utilizar os seus serviços e assumir as responsabilidades como membros, sem discriminaçóes por sexo, sociais, raciais, políticas e religiosas.

II. Gestão Democrática: As cooperativas são organizaçôes democráticas, controladas pelos seus membros, que participam ativamente na formulaçáo das suas políticas e na tomada de decisões.

III. Participação Econômica dos Membros: Os membros contribuem de forma equitativa para o capital das suas cooperativas e controlam-na democraticamente. Parte desse capital é, normalmente, propriedade comum da cooperativa. Os membros recebem, habitualmente e se houver, uma remuneração limitada ao capital integralizado, como condição de sua adesão.

IV. Autonomia e Independência: As cooperativas são organizaçóes autônomas, de ajuda mútua, controladas pelos seus membros.

V. Educação, formação e informação: As cooperativas promovem a educação e a formação dos seus membros, dos representantes eleitos e dos trabalhadores, de forma que estes possam contribuir, eficazmente, para o desenvolvimento das suas cooperativas.

VI. Interoperação: As cooperativas servem de forma mais eficaz aos seus membros e dão mais força ao movimento cooperativo, trabalhando em conjunto, por meio das estruturas locais, regionais, nacionais e internacionais.

VII. Interesse pela Comunidade: As cooperativas trabalham para o desenvolvimento sustentado das suas comunidades por meio de políticas aprovadas pelos membros.

Portanto, pela Organização das Cooperativas Brasileiras, o modelo cooperativista está alicerçado em valores como a participação democrática, a colaboração, a autonomia e a adesão voluntaria de seus associados (OCB, 2020). Além disso, segundo Pinto e Reisdorfer (2015) a governança cooperativa está embasada nos seguintes princípios:

Equidade de tratamento, transparência das informaçóes, prestação de contas responsável e responsabilidade corporativa, a cooperativa que seguir tais princípios estará mais propensa a alcançar a fidelidade dos seus cooperados, bem como institucionalizará um ambiente de confiança para todos os envolvidos nas atividades da cooperativa (PINTO; REISDORFER, 2015, p 44).

Logo, os princípios cooperativistas e a governança cooperativa podem contribuir no pensar e agir coletivamente, em um caminhar que pode conquistar a equidade, ampliar os processos 
de cooperação entre pessoas, cooperativas e escolas. Nesse tem-se presente os princípios as boas práticas no cooperativismo, como processos que podem auxiliar nos Projetos Interdisciplinares.

\subsection{Projetos interdisciplinares}

Parte-se do pressuposto de que é necessário antes de trabalhar Projetos Interdisciplinares, compreender o quesignifica a interdisciplinaridade na Educaçáo. Para Piaget a interdisciplinaridade pode ser entendida como: "o intercâmbio mútuo e a integração recíproca de várias ciências" (PIAGET, 1972, p.34). Deste modo, a interdisciplinaridade seria o encontro de diversas áreas do conhecimento, ou seja, a integraçáo de muitas disciplinas, a fim, de socializar o conhecimento a partir de um tema específico, em um caminhar, onde os princípios e as práticas de cooperação poderão ser importantes. Um processo que para Trindade, necessita compreender as práticas e teorias que auxiliam a "refletir sobre as atitudes que se constituem como interdisciplinares: atitude de humildade diante dos limites do saber próprio saber, sem deixar que ela se torne um limite; a atitude de espera diante do já estabelecido para que a dúvida apareça e o novo germine" (TRINDADE, 2008, p.73).

Portanto, o campo interdisciplinar pode ser entendido como uma esfera reflexiva dos saberes, que une as diversas áreas do conhecimento e agrega novas informaçóes. Para Trindade (2008), é importante ter presente a importância da cooperação, das trocas e dos encontros que conectam os indivíduos para as açôes interdisciplinares, instituindo transformaçôes na forma de aprender e compartilhar os conhecimentos. Já para Fazenda (2011), a importância reside nos caminhos que analisam a interdisciplinaridade como forma de superar a visão fragmentada dos conhecimentos. Significa que o aprendizado não pode se pautar ou ser de responsabilidade apenas de uma área especifica, mas sim, da união do conhecimento de todas as disciplinas, um movimento, que de certa fora se realiza entre os princípios do cooperativismo e as boas práticas de cooperação.

Deste modo, os professores são desafiados a trabalhar em um processo de transformação, sendo os responsáveis pela interação, reflexão e problematização dos conhecimentos para com seus alunos e a comunidade. Ressalta-se ainda que apenas uma "atitude interdisciplinar", possibilita progredir no processo de construção de uma prática onde, as ciências se completem para construir novas visões das realidades. Conforme aborda, Fazenda:

A interdisciplinaridade será possível pela participação progressiva num trabalho de equipe que vivencie esses atributos e vá consolidando essa atitude. É necessário, portanto, além de uma interação entre teoria e prática, que se estabeleça um treino constante no trabalho interdisciplinar, pois, interdisciplinaridade não se ensina, nem se aprende, apenas vive-se, exerce-se. Interdisciplinaridade exige um engajamento pessoal de cada um. Todo indivíduo engajado nesse processo será o aprendiz, mas, na medida em que familiarizar-se com as técnicas e quesitos básicos, o criador de novas estruturas, novos conteúdos, novos métodos, será motor de transformação. (FAZENDA, 2011, p.94):

Todavia, tem-se presente o significado educacional e a notoriedade que a Interdisciplinaridade e seus Projetos podem apresentar na contribuição dessa nova forma de pensar a educação, principalmente, ao buscar a reflexão com os estudantes em vulnerabilidade social, que fazem parte da Educação Popular que busca incluir a todos: "o negro, o índio, a mulher e não apenas o homem. Estes grupos e outros, historicamente excluídos, também têm conhecimento e isso leva a repensar a educação" (CORTEZE, 2011, p. 138). 
Nesse sentido, busca-se a Interdisciplinaridade e a em cooperação em Projetos Interdisciplinares, na perspectiva de contribuir e promover a equidade na educação. De tal modo, o termo projeto vem do latim projectu, e significa difundir uma ideia para frente (MAIA; SCHEIBEL; URBAN, 2009). Expandir o pensamento entre os sujeitos, semeando novas formas de pensar e ver o mundo. Hernández considera que projetos signifiquem:

a) O percurso por um tema-problema que favoreça a análise, a interpretação e a crítica (como contraste de pontos de vista). b) Onde predomine a atitude de cooperaçáo e onde o professor seja um aprendiz e não um especialista (pois ajuda aprender sobre temas que deverá estudar com os alunos). c) Um percurso que procure estabelecer conexóes e que questione a ideia de uma versão única da realidade. d) Cada trajetória é singular, e trabalhase com diferentes tipos de informaçáo. e) O professor ensina a escutar: do que os outros dizem também se pode aprender. f) Há diferentes formas de aprender o que queremos ensinar-lhes (e não sabemos se aprenderão isso ou outras coisas). g) Uma aproximação atualizada aos problemas das disciplinas e dos saberes. h) Uma forma de aprendizagem em que se leve em conta que todos os alunos podem aprender se encontrarem espaço para isso (HERNÁNDEZ, 1998, p. 183)

Desta forma, a metodologia de Projetos Interdisciplinares em sala de aula, pode contribuir no ensino aprendizagem dos estudantes, uma vez que, essa, deve partir da valorização, análise e da interpretação da crítica. Sendo assim, os Projetos precisam valorizar o aprendizado inicial dos estudantes, proporcionar momentos de troca, contextualização dos saberes e análise crítica, provocando uma nova visão sobre os conteúdos trabalhados.

Do mesmo modo, durante a aplicação dessa metodologia o professor deve ser o mediador do saber, e não o dono do saber, porquanto, o aprendizado se dá partindo da troca, da interaçáo das áreas do conhecimento, além disso, das informaçôes trazidas e vividas pelos alunos. É muito importante considerar esses saberes, uma vez que, partindo da realidade dos alunos e do que eles conhecem, podemos revelar uma nova possibilidade de análise e interpretaçáo da sua própria realidade. Como já mencionava Freire: “ensinar não é transferir conhecimento, mas criar as possibilidades para sua própria produção ou a sua construção" (FREIRE, 2017, p. 47).

Contudo, é importante não confundir a proposta que os Projetos Interdisciplinares exercem dentro de uma Escola, pois existe uma dicotomia muito grande quando abordamos sobre esse tema. Por vezes, as escolas acreditam estar realizando Projetos quando na verdade, estão apenas pendurando cartazes nas paredes. Lê-se em Nogueira (2001, p. 89): "qualquer cartaz pendurado na parede com desenho de três patinhos já é denominado: "Projeto Animais" reduzindo desta forma um projeto a mera elaboraçáo de cartazes” (FREIRE, 2001, p. 89).

Neste sentido a análise indica a elaboração de Projetos Interdisciplinares que partem de um objetivo amplo, maior do que o próprio tema a ser trabalhado, indo além do assunto abordado. Visando criar vínculos entre os professores, alunos, escola, comunidade, em um processo que pode ser capaz de desenvolver as habilidades propostas para a Educação Popular que inclui homens, mulheres e pessoas como seres coletivos, capazes de caminhar e esperançar um mundo mais justo (CORTEZE, 2011). Consequentemente, a acuidade que o estudo e a escola podem oportunizar, pode contribuir para a conquista de uma vida mais digna e menos injusta para com os estudantes. Como afirma Nogueira: "projetos pensados de forma bem mais ampla e abrangente é, a princípio, uma irrealidade que vai se tornando real, conforme começa a ganhar corpo a partir da realizaçáo de açóes e, consequentemente, as articulaçóes destas" (NOGUEIRA, 2001, p. 90). 
Por conseguinte, analisa-se que a educação através de projetos busca apreciar o contexto social, político, econômico, histórico e cultural de onde esses estudantes estão inseridos. Assim sendo, para que um Projeto apresente sucesso, ele precisa se pautar em alguns itens, como por exemplo, ter um problema para ser resolvido, questôes para serem levantadas, dúvidas e possíveis indicações de soluções. Todavia, o mais importante, é sempre considerar a contribuição que esses terão na formação do aluno. Formação essa, que vai além do conteúdo didático e da compreensão teórica, e, contudo, desenvolva o pertencimento do aluno aquele Projeto ou Escola, contribuindo para a mudança da sua realidade e de seus paradigmas.

Em vista disso, almeja-se que os Projetos Interdisciplinares interligados com os princípios e as boas práticas de gestão possibilitem para os estudantes, novas expectativas. De acordo com Paludo (2001, p. 43): "para as classes populares, a princípio, três caminhos se apresentam: contentarem-se com as esmolas e, não há outro nome para as assistências permanentes; viverem à margem, virando-se como podem; ou lutarem para democratizar a sociedade". Confia-se que a possiblidade da Interdisciplinaridade na escola seja capaz de contribuir em atitudes significativas na desmistificação do olhar sobre a educação, em escolas no interior, estabelecendo diálogos e práticas que contemplem a cooperação e a solidariedade.

\subsection{Princípios cooperativistas e projetos interdisciplinares}

Tem-se presente que os princípios cooperativistas e Projetos Interdisciplinares, necessitam responder com a participação dos atores sociais, para produzir não só transparência e o comprometimento, mas para construir uma nova realidade, seja em ambiente de organizaçóes cooperativadas, seja em ambientes escolares. Um processo que necessita suscitar boas práticas de governança. Essa concepção é fortalecida por Fontes Filho, Marucci e Oliveira (2008), ao defenderem que os princípios cooperativistas são importantes para alimentar uma linha norteadora nas práticas de educação cooperativista, certamente com boas perspectivas em práticas na Educação Popular, uma vez que, em organizaçôes cooperativista, de orientação na economia solidária, os princípios cooperativistas são bem aceitos e incorporados em suas práticas de governança.

Assim, registra-se que os sete princípios do cooperativismo (PCF, 2021) e o Manual das Melhores Práticas de Governança (OCB, 2016), advertem que o primeiro princípio: Adesão Livre-as cooperativas, são organizaçôes voluntárias, que oferecem condiçôes para que todas as pessoas sejam aptas a utilizar os seus serviços, assumir as responsabilidades como sócio, sem discriminaçóes no que se refere ao sexo, raça, política, social e religiosa. Podendo integrar o quadro associativo de uma cooperativa, indicando um norte, a inclusão social. Significa, que tanto a cooperativa, como a escola necessitam criar um ambiente plural, onde a multiplicidade se completa e se ramifica dentro da diversidade. Este princípio cooperativista está intimamente ligado com valores relacionados a liberdade e a igualdade, o que se vincula-os perfeitamente com os objetivos da escola e da interdisciplinaridade.

O segundo princípio do cooperativismo: Gestão Democrática indica as cooperativas como organizaçôes democráticas, criadas, administradas, controladas pelos sócios, que participam e deliberam a formulação das políticas e a tomada de decisóes na cooperativa, seja ela mais voltada para as atividades empresariais ou para o campo da economia solidária. Este princípio pode dialogar com a educação, os Projetos, por contemplar a presença dos professores e os alunos, 
ao trabalhar suas realidades, o que eles conhecem e convivem. Portanto, remete a possibilidade de escuta, apelos e sugestôes. Auxiliando os Projetos na realização do processo democrático e permitindo que os alunos se tornem seres ativos e participativos dentro da sociedade.

Já o terceiro princípio cooperativista está ligado a participação econômica, onde os associados de uma cooperativa necessitam contribuir de forma econômica com sua cooperativa, por serem os donos do empreendimento. Todos têm de fazer sua parte, de modo que o esforço seja individual e proporcionalmente distribuído. Aqui está a ajuda mútua, a solidariedade. Assim sendo, este princípio está interligado a Educação Popular, uma vez que, as Escolas pertencem a todos os membros que fazem parte dela, alunos, professores, funcionários, direçóes, pais e a comunidade. Nesse sentido, almeja-se que os Projetos tenham a capacidade de provocar o sentimento de pertencimento ao local, as suas realidades, ao cuidado da Escola como uma referência positiva ao seu aprendizado. Destacamos que a Educação mesmo com seus problemas estruturais, é compreendida como um instrumento a serviço da democratização. Devendo contribuir nas vivências dos grupos sociais, no diálogo, na crítica, no crescimento, desenvolvimento intelectual e pessoal de seus estudantes. Então, esse processo na escola não se limita as contribuiçóes econômica dos integrantes no ambiente escolar, mas sim, a destinação de seus trabalhos, na construção de um ambiente fraterno e solidário.

O quarto princípio relaciona-se: Autonomia e Independência, que explica o empreendimento cooperativo ser de natureza autônomo e independente, construído pelo quadro de sócios. Uma conjugação de esforços realizado pelos sócios, pela autogestão. Significa que o sucesso ou o insucesso do empreendimento afeta unicamente associados, pelo fato de a gestão ser exclusividade dos associados. Logo, pode-se estabelecer um diálogo com os Projetos, pois para que se obtenha êxito, estes precisam ser autônomos e independentes. Sendo assim, as escolas precisam ser autônomas nas suas escolhas, já que, cada uma está inserida dentro de uma realidade diferente. E neste ponto, cada uma deve partir da sua realidade para alcançar o sucesso de seus Projetos, e principalmente, para alcançar os objetivos propostos nos Projetos. Quando se fala em autonomia e independência, aponta-se princípios que norteiam qualquer escola, e por sua vez, os seus alunos, professores, funcionários e a comunidade. Prontamente, busca-se a escola um local onde os estudantes possam conquistar a autônima, independência e criticidade.

O quinto princípio: Educação, Formação e Informação pode-se remeter de forma automática a sua articulação com a educação, a importância que esta assume dentro do contexto do cooperativismo, uma vez que, as cooperativas necessitam promover a educação e a formação do seu quadro de funcionários e associados, para que esses possam contribuir, eficazmente, para o desenvolvimento das suas cooperativas.

Dessa forma, o quinto princípio vincula-se a cooperação, ajuda mútua, ao auxílio entre os seus cooperados. Em seguida, este princípio pode dialogar com a Interdisciplinaridade, porquanto, a educação e seus Projetos estão ligados ao processo de cooperar. Sendo assim, nenhum trabalho consegue desenvolver-se sem a união de todos em prol de um objetivo comum. Esta prática necessita de açóes de cooperação, para trabalhar a interdisciplinaridade nas diversas áreas do conhecimento, uma vez que, cooperar é compartilhar os saberes. Destaca-se ainda o enunciado trazido neste princípio: Educação, Formação e Informação, como um processo indispensável na realização de propostas Interdisciplinares, já que, estes trazem primeiro a possibilidade de educar formalmente os indivíduos dentro de conceitos e conteúdo. Na sequência, formam, preparam e informam os estudantes para novos desafios, sobretudo, para a convivência em grupo e na busca de soluçôes coletivas. 
O sexto princípio aponta a Intercooperação, onde as cooperativas servem de forma mais eficaz aos seus quadros de sócios, ao oportunizarem ambientes de intercooperação entre os ramos do cooperativismo. Significa trabalhar em conjunto com outras cooperativas, tanto em nível local regional, nacional e internacional. A referência e ligação na Interdisciplinaridade se dá, considerando a Intercooperaçáo de toda a Escola para o desenvolvimento de um trabalho.

Portanto, um Projeto não se faz sozinho, mas sim, parte da uniáo de todos os membros deste local, professores, funcionários, alunos, coordenaçôes, pais e toda comunidade escolar. Entretanto, dentro deste componente tem-se um princípio básico a considerar, que está relacionado a construção de Projetos ampliados, ou seja, vinculados a outras Escolas ou comunidades. Assim sendo, estes desenvolvem-se partindo da união de escolas distintas que realizam a construção do conhecimento na interlocução dos saberes diversos. Um exemplo deste apontamento, são escolas de estados distintos que através de Projetos conseguem transferir os conhecimentos mesmo à distância, corroborando no processo da cooperação e do aprendizado.

O último princípio cooperativista é o Interesse pela Comunidade, especialmente onde as cooperativas estão inseridas. Indica que as cooperativas necessitam trabalhar para o desenvolvimento sustentado das suas comunidades, ao realizar um conjunto de atividades aprovadas pelo seu quadro de sócios, indicando açóes e políticas para responder demandas da comunidade. Dentro deste princípio pode-se destacar principalmente, a sua relação comunitária, ou seja, a ideia de pensar no coletivo, com açóes que envolvam toda a sociedade e não apenas os cooperados por ela.

Desse modo, o Interesse pela Comunidade relaciona-se na inclusão das famílias e dos alunos no desenvolvimento dos Projetos Interdisciplinares, nas relaçóes estabelecidas entre escola e a comunidade escolar. Consequentemente, quando a escola e família unem-se em prol do aprendizado este se dá, de forma ampla e significativa. Consideramos ainda, a relação estabelecida quando lembramos que: "as cooperativas devem respeitar as peculiaridades sociais e a vocação econômica do local, desenvolvendo soluçóes de negócios e apoiando açóes humanitárias" (PCF, 2021). Em consequência, os Projetos Interdisciplinares também estão ligados a respeitar características locais, e principalmente, em dar oportunidade de aprendizados significativos para os alunos. Por conseguinte, estes reverterão no desenvolvimento de uma sociedade politizada e humana.

\section{Caminhos metodológicos}

A sociedade vive em um movimento de grandes mudanças, de incertezas, onde os mapas cognitivos coletivos e individuais, passam por enormes desafios, na forma de pensar e agir, o que oportuniza um ambiente fértil para pesquisas que trilham os princípios cooperativistas, que dialogam com estudos e propostas Interdisciplinares na Educação. Um processo que necessita contar com aportes teóricos-metodológicos, para a compreensão da realidade, o que indica um trilhar metodológico, que é corroborado por González-Rey (2011), enquanto um processo de pesquisa e aprendizagem, para além da cooperação, necessita contar com relaçóes de trabalho, entre educadores e educandos, para mergulhar em um processo subjetivo, que contempla a produção simbólico-emocional. Esse caminhar faz com o educando, deixa de lado o campo passivo, se envolve em uma condição ativa, o que implica em um posicionamento próprio e singular no 
processo de aprender, desafiando náo só os educadores, mas também, fundamentalmente os pesquisadores.

Portanto, a presente pesquisa se apresenta como sendo um procedimento racional e sistemático, que tem por objetivo apresentar respostas frente a um conjunto de práticas ainda insuficientes respondidas sobre a realidade (GIL, 2002). Assim, a pesquisa se classifica, quanto à natureza, como aplicada, seguindo a trilha metodológica de Zamberlan et al. (2014).

Por conseguinte, para além da pesquisa aplicada, a pesquisa conta a abordagem qualitativa, que permite um diálogo amplo, com uma complexa rede de termos, conceitos e suposiçóes, relacionados aos estudos educacionais, culturais e interpretativos (DENZIN; LINCOLN, 2006). Para Minayo (1994), a pesquisa qualitativa, responde a questóes muito particulares, com um nível de realidade que não pode ser quantificado e sim, exposto e interpretado, pelos próprios pesquisados. Significa mergulhar na realidade social, que é mais complexa do que a própria teoria, que neste estudo conta com entrevistas semiestruradas.

No entanto, é importante registrar que nas abordagens qualitativas, as verificaçóes mergulham em pesquisas epistemológicas. Para González-Rey, (2005), o caminho da epistemologia faz compreender que a pesquisa necessita de um processo permanente da produçáo de ideias. Esse caminhar pode ser enriquecido pelos pesquisadores, ao organizarem os cenários complexos, pelos diálogos históricos dos objetos de estudos, trilhando caminhos e realidades para encontrar respostas, frente as necessidades, que neste estudo é o ambiente escolar, para assim uma maior compreensão. Um processo onde não é suficiente um olhar linear, e sim, uma caminhada onde o pesquisador e o ambiente pesquisado assumem um papel ativo no desenvolvimento da pesquisa, nos caminhos da complexidade, que se encontram os elementos para a elaboraçáo das concepçóes epistemológicas (GONZÁLEZ-REY, 2005).

Ainda, para González-Rey (2003), pesquisas que trabalham com abordagens qualitativas trilham campos epistemológicos que auxiliam na compreensão das diferentes configuraçóes subjetivas dos sujeitos (que neste estudo é o ambiente escolar), estabelecendo processos de ensino/ aprendizagem. Por consequência, é possível identificar a presença da teoria da subjetividade, na produçáo construtiva interpretativa, no caráter interativo e no contexto histórico que os sujeitos estão envolvidos, para entender a forma única e diferenciada da constituição subjetiva.

Desta forma, em Cardinalli (2006), suas contribuiçóes científicas apresentam a necessidade da interpretação da subjetividade, que ultrapassa as questóes aparentes, indica a necessidade de uma investigaçáo, onde tem-se de ter presente a realidade dos sujeitos, onde a subjetividade se manifesta de forma distinta. Ainda, para autora, embora ocultas, as realidades das subjetividades influenciam e são influenciados pelo ambiente escolar, e por isso não devem ser ignorados pelos profissionais nele inseridos e que se comprometem com a formação global de seus alunos.

Ainda merece registro, a interpretação dos resultados conta com a Análise de Conteúdo de Bardin (2010), como sendo um conjunto de técnicas e procedimentos sistemáticos para a compreensão, de como os princípios cooperativistas podem contribuir no processo de elaboração de propostas Interdisciplinares na Educação. 


\section{Análise e discussão dos resultados}

É pertinente ter presente, ao interpretar os resultados de uma pesquisa, verificar de como foi planejado o caminho do processo de aprendizagem, especialmente em se tratando de um ambiente escolar. Assim, tem-se um olhar planejado. Para Vasconcellos (2009), planejar é antecipar açôes, com possibilidades de conquistar certos objetivos, que vêm de necessidades criadas por uma determinada realidade. Significa um pensar e agir de acordo com um plano.

Desta forma, a escola pode contar com um planejamento integrado, com metodologias interdisciplinares, com a presença dos princípios cooperativistas. Um caminhar que fortalece a cidadania, onde a interdisciplinaridade propóe mudanças práticas de ensino, especialmente a quebra de estruturas fundamentadas no isolamento das disciplinas.

A pesquisa indica que o movimento pela fragmentação, repetição ou sombreamento dos conteúdos foi ampliado, pela contribuição dos professores, presente no Projeto da escola. A interdisciplinaridade, dos conteúdos de uma determinada área são trabalhados de forma integrada na perspectiva da construçáo coletiva e integrada de ideias. Dessa forma, a análise buscou verificar o case de sucesso realizado em uma Cooperativa Escolar na cidade de Espumoso, localizada no interior do Rio Grande do Sul.

Em vista disso, a entidade escolhida para esta análise é a Cooperativa Escolar Imaculada Conceição - COOPERIC, localizada na comunidade do Depósito, interior da Cidade de Espumoso, sobe a gestão da professora Andreia Borba de Oliveira. A Cooperativa em questáo foi fundada em 2018 e conta com 26 alunos cooperados, ligados diretamente as atuaçóes da cooperativa, para além, de forma indireta com 82 alunos que estáo vinculadas e este projeto, bem como, esse trabalho foi acolhido pela Secretária de Educação do município de Espumoso, Magali Pereira de Oliveira.

Nossa Cooperic- Cooperativa Escolar dos Alunos da Escola Municipal de Ensino Fundamental Imaculada Conceição do Depósito, Distrito de Espumoso, foi fundada em 10 de setembro de 2018, após um ano de estudo sobre os princípios, pilares do cooperativismo e toda estrutura documental que fundamenta a estruturação de uma cooperativa, visitas de imersão em escolas da regiáo da Serra Gaúcha, berço do cooperativismo. Somos a Cooperativa Escolar pioneira da regiáo do SICREDI Espumoso-RS/MG.

Em vista de entender acuidade da cooperativa escolar, nesta comunidade, foi elaborado uma entrevista com a Secretaria de Educação do município, Magali Pereira de Oliveira, Diego Piovesan de Ramos Assessor de Desenvolvimento do Cooperativismo na Cooperativa Sicredi Espumoso RS/MG e a Coordenadora Pedagógica do Projeto, Professora Tais Pierezan Klein. Significa a uniáo de várias entidades comprometidas com a equidade e igualdade na educaçáo, pois, a Cooperativa Escolar estudada tem no seu alicerce a uniâo da Escola, da Secretaria de Educação e do Sicredi como grandes parceiros na construção do conhecimento, o que corrobora em açôes cooperativas na Educação (GAMBETTA, 1996).

Evidencia-se clara compreensão dos entrevistados sobre a influência que as açóes de cooperação podem exercer sobre o desenvolvimento educacional: "os alunos cooperados são incentivados ao protagonismo, aplicando na vida conteúdos e temas abordados em sala de aula. É uma forma de significar e resinificar o currículo", segundo Tais Pierezan Klein (2021). As alocuçôes das entrevistas, remetem ao entendimento de que a colaboraçấo aliada 
a interdisciplinaridade pode contribuir para o desenvolvimento de uma educação mais justa e igualitária Trindade (2008). O que se evidencia nas falas a seguir:

Ter o privilégio de acompanhar a vivência dessa realidade em nossas escolas é o que nos possibilita testemunhar a importância das Cooperativas Escolares no desenvolvimento pessoal, cognitivo dos alunos. Pois, incentivar o protagonismo de adolescentes e jovens proporcionando a vivência do modelo cooperativista no ambiente escolar é um dos objetivos das cooperativas escolares (MAGALI PEREIRA DE OLIVEIRA).

Tenho total convicção da contribuição genuína do cooperativismo para o desenvolvimento educacional de alunos e além, de toda comunidade escolar. Os projetos cooperativistas oportunizam um ambiente de cidadania e democracia. Levando o protagonismo de cada indivíduo para as relaçóes interpessoais, que são construídas com muito respeito. Isso permite se criar um ambiente de desenvolvimento educacional, pois impacta diretamente nos conteúdos aprendidos em sala de aula. Os alunos que participam de projetos cooperativistas, aprendem a ter maior respeito e postura de dedicação frente aos seus estudos, sendo mais focados e entusiasmados a conhecer, exercitando a curiosidade e a descoberta (DIEGO PIOVESAN DE RAMOS, 2021).

Assim, tem-se presente que os Projetos Cooperativistas contribuem para uma nova interpretação de realidades, ao passo que contribui para o protagonismo estudantil dando oportunidade únicas de aprendizados significativos para a vida. É nessa perspectiva, ao contribuir com açôes que fortalecem a aplicabilidade dos conteúdos ministrados nas salas de aula, uma vez que, os alunos passam a focar mais em seus estudos e aprendizagens. Nesse sentido também é relevante compreender a visão dos entrevistados sobre o processo da cooperação na Cooperativa Escolar. Para esta apreciação foi realizada a seguinte pergunta: $\mathrm{O}$ que você compreende por Cooperativismo Escolar?

As cooperativas escolares são um modelo de conhecimento do espírito e da prática cooperativista, focado na liderança e no protagonismo juvenil, uma verdadeira iniciação ao cooperativismo, seus valores e princípios (MAGALI PEREIRA DE OLIVEIRA, 2021).

Cooperativismo escolaré um modelo de estudo sobre os princípios e as práticas cooperativistas que ocorre em ambiente escolar, como um laboratório que oportuniza aos alunos cooperados a busca de conhecimentos por uma metodologia aberta, ativa e que permite a exploração e o protagonismo. Esta forma de estudo está conectada aos demais conteúdos trabalhados em sala de aula, fazendo comunicaçáo com a BNCC. [...]. O cooperativismo no ambiente da escola, abre muitas possibilidades para os professores desempenharem com mais eficácia seus conteúdos em sala de aula ou em ambientes extraclasse. Os alunos, por sentirem-se responsáveis e protagonistas de suas trajetórias, devido aos cargos assumidos na cooperativa escolar, passam a ter uma postura de maior respeito e concentração nas demais matérias. Também é possível ver a aproximação dos familiares e da comunidade escolar nas ações e no cotidiano da escola. O que permite formar uma rede de apoio e um espaço de inclusão social (DIEGO PIOVESAN DE RAMOS, 2021).

As respostas fortalecem a concepção de que as açôes cooperativistas estão ligadas a interdisciplinaridade na educação, já que, estabelecem uma conexão entre ambas, aproximando e conectando professores, alunos, disciplinas, escolas e famílias. Desta forma, o cooperativismo escolar oportuniza aos educandos analisa e compreender os princípios cooperativistas que norteiam o sistema/movimento das cooperativas, dando voz e vez aos alunos, que de outra forma provavelmente não seriam ouvidos. Salienta-se ainda, que esta oportunidade de cooperação: "possibilita o desenvolvimento dos educandos nas mais diversas áreas do conhecimento, além de 
estimular a preocupação com o social, senso de responsabilidade, empreendedorismo e liderança" para Tais Pierezan Klein.

Portanto, ao buscar a compreender a acuidade da COOPERIC, enquanto um movimento da comunidade escolar, tem-se presente nesta caminhada, o desenvolvimento dos princípios cooperativistas, registrado pelos entrevistados, ao relacionar as açóes da Cooperativa Escolar. Deste modo, os relatos foram amplamente parecidos, pois todos os entrevistados mencionaram a importância do Projeto, um caminho a ser trilhado com grandes oportunidades de crescimento e desenvolvimento de açóes para toda a comunidade escolar. Entre elas, a pesquisa identificou a preocupação dos alunos quanto aos elevados índices de hipertensão na comunidade:

O objeto de aprendizagem produzido pela Cooperic foi o 'sal temperado'. O qual foi escolhido pelos sócios, após estudo da realidade da comunidade do Depósito que mostra índices autos de hipertensão, o que levou a necessidade de conscientização dos mesmos referente aos benefícios da ingestão controlada de sal. Através da produção do Sal Temperado como fonte alternativa para redução do consumo de sal, foi possível reduzir os índices de hipertensão e conscientizar a comunidade (MAGALI PEREIRA DE OLIVEIRA, 2021).

Evidencia-se desta forma, que as açóes da cooperativa escolar ultrapassaram os espaços da sala de aula, expandindo-se para toda a comunidade, com a confecção do sal temperado, que para além de controlar os índices de hipertensão das pessoas, levou a conscientização a respeito do uso abusivo do sal na alimentação. Outro ponto a ser destacado no trabalho da COOPERIC, vincula-se: "a participação ativa nas açóes da comunidade escolar, engajamento, cidadania e o desenvolvimento da oratória”, apontado pelos registros da Tais Pierezan Klein (2021). Portanto, é primordial lembrar que as cooperativas escolares náo visam lucros, e sim, uma atividade de consciência social.

$\mathrm{Na}$ expectativa de concluir a abordagem sobre a importância das ações cooperativistas e sua ligação com a interdisciplinaridade. Notou-se nas alocuçôes várias falas importantes para a compreensão e interpretação a respeito desta temática:

A cooperativa proporciona açôes em benefício da Comunidade Escolar e em geral com diversas parcerias, como: plantio e cultivo de hortaliças na estufa da escola, parceria com a JCI de Espumoso, no projeto JCI do bem, contribuindo no embelezamento da escola [...]. Destaco entre as contribuiçôes da Cooperativa escolar, o desenvolvimento da comunicação, oratória, espírito de equipe, cooperação, liderança e empatia, além do conhecimento das atividades econômicas, sociais e culturais em benefício dos associados, os cooperados aprendem através, da adesão livre e voluntária, sobre gestão democrática, autonomia e independência, intercooperação e o compromisso com a comunidade (MAGALI PEREIRA DE OLIVEIRA, 2021).

Vejo com muito orgulho os trabalhos produzidos pelos alunos e com muito respeito e admiraçáo a condução destes trabalhos realizados pelos professores e gestores da educaçáo. É notório o crescimento de um aluno ao participar de um programa que esteja alicerçado no cooperativismo, as práticas intrínsecas dos princípios do cooperativismo nas atividades desenvolvidas, transformam a realidade de muitos alunos e famílias, que abrem olhos para novas possibilidades, para aprender aquilo que nunca alguém falou. [...] O cooperativismo gera oportunidades de mudanças e impactos positivos em nossa comunidade. Não há melhor lugar para transformar nossas comunidades do que o ambiente escolar, e unir este ambiente de possibilidades com as práticas cooperativistas, com certeza nos levarão a ter orgulho da nossa construção no futuro (DIEGO PIOVESAN DE RAMOS, 2021). 
Portanto, verifica-se que os princípios cooperativistas são os grandes norteadores das açóes das cooperativas escolares e por sua vez, estão interligadas as ideias dos Projetos interdisciplinares, na medida em que buscam o intercâmbio mútuo do saber (PIAGET, 1972). Para finalizar se faz necessário analisar a notoriedade das parcerias estabelecidas entre as entidades sejam elas educacionais ou não. Conforme a transcrição:

$\mathrm{Na}$ cooperativa onde trabalho, Sicredi Espumoso RS/MG, desenvolvemos vários programas voltados a educação cooperativista e suas possibilidades. Os programas são construídos por várias mãos, parcerias entre a Cooperativa e as Secretarias Municipais de Educação, com apoio da Fundaçáo Sicredi, através de Assessorias Pedagógicas especializadas. Os principais cases que possuímos podem ser visualizados por faixa etária das crianças e jovens participantes. Educação Infantil e Ensino Fundamental: Programa A União Faz a Vida: voltado a descoberta, ao estímulo da curiosidade [...]. Ensino Fundamental (Anos Finais): Programa Cooperativas Escolares: os alunos de $5^{\circ}$ a $6^{\circ}$ ano, formam uma cooperativa escolar, e por um objeto de aprendizagem, desenvolvem estudos cooperativistas, educação financeira, empreendedorismo, inclusão [...]. Ensino Médio: Programa de Jovens Associados: os alunos são convidados a participarem do Sicredi no contra turno da escola [...]. Classificação da informação: Uso Interno E Programa de Educação Financeira: que ocorre com materiais e práticas realizados pelos professores nas Secretarias e Escolas parceiras. Com estudos semanais sobre economizar, construir sonhos de curto, médio e longo prazo, ajudar na realização dos sonhos coletivos... entre outros assuntos e possibilidades de desenvolvimento do tema (DIEGO PIOVESAN DE RAMOS, 2021).

Logo, todas as alocuçôes realizadas pelos entrevistados vislumbram uma possibilidade de sucesso no âmbito escolar, quando açóes vinculadas a cooperação e interdisciplinaridade estão interligadas. Sendo assim, o sucesso no processo educacional dialoga de forma direta com os princípios de cooperação. O que fica evidenciado pela pesquisa: "queremos deixar filhos melhores para nossas comunidades e comunidades melhores para nossos filhos. A educação e o cooperativismos são aliado essenciais para esse futuro esperado" (DIEGO PIOVESAN DE RAMOS, 2021).

\section{Consideraçóes finais}

O artigo apresenta como centralidade, a análise de como se efetivaram as práticas de cooperação, para compreender as contribuiçôes dos princípios do cooperativismo, as boas práticas de governança e a interdisciplinaridade podem contribuir no processo em Projeto Educacional. Um Projetos Interdisciplinar, na Cooperativa Escolar dos Alunos da Escola Municipal de Ensino Fundamental Imaculada Conceição, no Distrito de Depósito, em Espumoso, no Rio Grande do Sul.

Portanto, tem-se presente que a partir da formação da Cooperativa Escolar, em 10 de setembro de 2018, uma nova perspectiva educacional foi efetivada na prática, tendo como eixos norteadores os princípios do cooperativismo, as boas práticas de governança e a interdisciplinaridade. Esse conjunto de pilares, se consolidaram na prática, consolidaram uma estrutura documental, que fundamenta a organizaçáo cooperativa, um conjunto de açóes que interviram na realidade, especialmente, ao produzir o sal temperado, para uma comunidade com altos índices de hipertensão, ao promover o protagonismo de estudantes, ao exercerem a 
autogestão na cooperativa, tendo como aliados o SICREDI Espumoso-RS/MG e a Secretaria Municipal da Educação.

Portanto, significa que os valores e os princípios do cooperativismo estão em sintonia com os conceitos de cidadania, solidariedade, cooperaçáo, fortemente ligados ao Projeto da escola. Significa, a possibilidade da educação, estar em contato com as comunidades do interior, periféricas. Dessa forma, a uniáo dos princípios com as metodologias interdisciplinares, podem contribuir significativamente na fusão entre os princípios cooperativistas e a educação que busca a presença dos estudante, professores, funcionários, pais e comunidade.

Por conseguinte, o estudo permite vincular os princípios cooperativistas, as boas prática de governança com as metodologias de Projetos Interdisciplinares, em uma perspectiva de pensar e planejar novos procedimentos educacionais, com possibilidades de transformar a realidade das escolas. Significa, trabalhar e contextualizar os conteúdos em sala de aula que podem estabelecer novas aprendizagens para os alunos e professores, em um processo que pode unir os conteúdos didáticos, as novas concepçóes e metodologias, resinificando o conhecimento, tendo por base os princípios do cooperativismo, a presença do pensamento interdisciplinar, a busca na escola de novos paradigmas no processo educacional.

Certamente, a Cooperativa Escolar, é uma proposta inovadora, inserida na caminhada em busca de uma outra sociedade, mais democrática, inclusiva, solidária. Acredita-se que esse processo é possível com a presença dos princípios cooperativistas, das boas práticas de governança, a interdisciplinaridade, estabelecendo uma interlocução de saberes educacionais, nos Projetos Pedagógicos. Consequentemente, esse processo pode constituir para uma ótima alternativa no avanço da educação, principalmente, quando se pensa em estudantes de baixa renda, em comunidade no interior, em ambiente periféricos, dando uma nova vida em escolas, comunidade, com esperança de conquistar novos horizontes, um espaço nesta sociedade táo desigual e injusta com tanta gente.

Para finalizar, destaca-se que o conjunto dos elementos doutrinários do cooperativismo, em um movimento internacional, nacional, local, necessitam contribuir com a comunidade escolar, seja pela educação, seja pela efetivação da autonomia, pelo interesse pela comunidade, desafiando as cooperativas em uma caminhada de inserção na comunidade para auxiliar na superação dos desafios pedagógicos, estruturais, formais nas escolas, imprimindo os princípios da cooperação, da democratização e da justiça social, nas vivências escolares, para conquistar o desenvolvimento intelectual e pessoal da comunidade escolar. Como destaca Freire: "a transformação da educação não pode antecipar-se à transformação da sociedade, mas esta transformação necessita da educação" (FREIRE, 2001, p. 84).

\section{Referências}

BARDIN, L. Análise de conteúdo. 4. ed. Lisboa: Ediçôes70, 2010.

CARDINALLI, C. Uma análise da configuraçâo subjetiva do aluno com dificuldades na aprendizagem. Dissertação de Mestrado em Psicologia, Pontifícia Universidade Católica de Campinas, Campinas, SP, 2006 
CORTEZE M. (2011). Educação Popular e Cooperação na Escola Pública. Revista Contexto \& Educação. Disponível em: https://doi.org/10.21527/21791309.2011.85.137-156 Acesso em: março. 2021.

DALLABRIDA, V. R. Governança Territorial: do debate teórico à avaliação da sua prática. Revista Análise Social, n. 215, v. L (2º), 2015.

DENZIN, N. K.; LINCOLN, Y. S. Introdução: a disciplina e a prática da pesquisa qualitativa. (Org.) DENZIN, N. K.; LINCOLN, Y. S. Planejamento da pesquisa qualitativa: teorias e abordagens. Porto Alegre: Artmed, 2006.

FAZENDA, I. Interdisciplinaridade: história, teoria e pesquisa. 4. ed. Campinas: Papirus, 1999.

FAZENDA, I.C.A. Integraçáo e interdisciplinaridade no ensino brasileiro: efetividade ou ideologia. 6 ed. São Paulo: Ediçóes Loyola, 2011.

FRANCISCO FILHO, J.; LINS, L. S. Fundamentos e Análises das Demonstraçóes Contábeis: uma Abordagem Interativa. São Paulo: Atlas, 2012.

FONTES FILHO., J. R.; MARUCCI, J. C., OLIVEIRA, M. J. Governança cooperativa: participação e representatividade em cooperativas de crédito no Brasil. Revista de Contabilidade e Organizaçóes. São Paulo, 2008.

FREIRE, P. Pedagogia do oprimido. 31. ed. Rio de Janeiro: Paz e Terra, 2001

FREIRE, P. Pedagogia da autonomia. São Paulo: Paz e Terra, 2017.

GAMBETTA, D. Confiança e cooperação. In W. Outhwaite, T. Bottomore, (Eds.), Dicionário do pensamento social do século XX (pp.119-120). Rio de Janeiro: Jorge Zahar Editor, 1996.

GIL, A. C. Como elaborar projetos de pesquisa. 4. ed. - São Paulo: Atlas, 2002

GONZÁLEZ-REY, F. Sujeito e subjetividade. São Paulo: Pioneira, 2003.

GONZÁLEZ- REY, F. Pesquisa qualitativa e subjetividade: os processos de construção da informação. São Paulo: Editora Pioneira Thomson, 2005.

GONZÁLEZ-REY. F. Lenguaje sentido y subjetividad: más alla del lenguaje y la conducta. Estudios de Psicologia, v. 32, 2011.

HERNÁNDEZ, F. A organizaçáo do currículo por projetos de trabalbo. Porto Alegre: Artes Médicas, 1998.

ICA - International Co-operative Aliance. Co-operatives Principles. Disponível em:http:// www.ica.coop/ica/en/principles.html Acesso em: março. 2021.

MAIA, C.M.; SCHEIBEL, M.F.; URBAN, A.C. Didática: organização do trabalho pedagógico. Curitiba: IESDE Brasil S.A., 2009. 
MOURA, D. G. de. Trabalhando com projetos: planejamento e gestão de projetos educacionais. Petrópolis, RJ: Vozes, 2006.

MINAYO, M. C. de S. (Org.). Pesquisa social: teoria método e criatividade. $1^{\text {a }}$ ed. Petrópolis, RJ: Vozes, 1994

NOGUEIRA, N.R. Pedagogia dos projetos: uma jornada interdisciplinar. São Paulo: Érica, 2001.

OCB - ORGANIZAÇÃO DAS COOPERATIVAS BRASILEIRAS. Evolução do cooperativismo no Brasil. 2020. Disponível em: http://www.ocb.org.br/site/cooperativismo/ evolucao_no_brasil.asp Acesso em: dez de 2020.

OCB - Organização das Cooperativas Brasileiras. Manual de Boas Práticas de Governança para Cooperativas. Brasília. 2016.

PALUDO, C. Educaçáo popular em busca de alternativas: uma leitura desde o Campo democrático e popular. Porto Alegre: Tomo Editorial; Camp 2001.

PCF- PORTAL DO COOPERATIVISMO FINANCEIRO. Os 7 princípios universais que regem o cooperativismo. 2021. Disponível em: https://cooperativismodecredito.coop. $\mathrm{br} /$ cooperativismo/historia-do-cooperativismo/os-7-principios-do cooperativismo/ Acesso em maio de 2021.

PIAGET, J. Méthodologie des Relations Interdisciplinaires. Archives de Philosophie, 1972.

PINTO, N.G.M.; REISDORFER, V.K. Governança Cooperativa. Santa Maria: UFSM, 2015.

REY, G. F. L. Sujeito e Subjetividade: uma aproximação histórico-cultural. São Paulo: Thomson Learning, 2003.

REY, G. F. L. O social na Psicologia e a Psicologia Social: a emergência do sujeito. Petrópolis: Pioneira Thomson, 2004.

REY, G. F. L. O valor heurístico da subjetividade na investigação psicológica. In: GONZALEZ REY, F. L. (Org). Subjetividade, Complexidade e Pesquisa em Psicologia. São Paulo: Thompson Learning, 2005.

ROSSETTI, J. P.; ANDRADE, A. Governança Corporativa: Fundamentos, Desenvolvimento e Tendências. (6a. ed.). Sáo Paulo: Atlas, 2012.

SCHNEIDER, J. O. A Doutrina do Cooperativismo: Análise do Alcance, do Sentido e da Atualidade dos seus Valores, Princípios e Normas nos Tempos Atuais. Revista do Centro Interdisciplinar de Desenvolvimento e Gestão Social - CIAGS \& Rede de Pesquisadores em Gestão Social - RGS, v. 3 (2). P.251-273, jul/dez.2012

TRINDADE, D.F. Interdisciplinaridade: um novo olhar sobre as ciências. In: FAZENDA, I. (org.). O que é interdisciplinaridade? São Paulo: Cortez, 2008. 
VASCONCELLOS, C. S. Planejar é antecipar açóes para atingir certos objetivos. 2009. Disponível em: http://revistaescola.abril.com.br/planejamento-eavaliacao/planejamento/ planejar-objetivos-427809.shtml. Acesso em 10 maio.2021.

VERGARA, S. C. Projetos e relatórios de pesquisa em administraçáo. 3.ed., São Paulo: Atlas, 1997.

ZAMBERLAN, L C; SOUZA, J. D. S.; GRISON, A. J.; GAGLIARDI, A. O.;TEXEIRA, E. B.; DREWS, G. A.; VIEIRA, E. P.; BRIZOLLA, M. M. B.; ALLEBRANDT, S. L. Pesquisa em ciências sociais aplicadas. Ijuí: Ed. Unijuí, 2014 